\title{
Testing Greenfield run-off estimation techniques using high-resolution field observations
}

\author{
H.J.E. Rodda ${ }^{1}$ and J. Hawkins ${ }^{2}$ \\ 1 Hydro-GIS Ltd, Chalgrove, Oxfordshire, UK \\ 2 North Wyke Research, Okehampton, Devon, UK
}

\author{
Correspondence \\ Harvey J.E. Rodda PhD, Hydro-GIS Ltd, \\ 10 Coles Lane, Chalgrove, Oxfordshire, \\ Oxford OX44 7SY, UK \\ Email: harvey.rodda@hydro-gis.co.uk
}

DOI: 10.1111/j.1753-318X.2012.01156.x

\section{Key words}

Land-use management; measurement; modelling; rainfall.

\begin{abstract}
The current UK guidelines for sustainable drainage systems design [Department of the Environment Food and Rural Affairs/Environment Agency (DEFRA/EA), 2005; Construction Industry Research and Information Association (CIRIA), 2007] require that the design peak flow from a new development should not exceed that which would occur under the pre-development or Greenfield conditions. Although these guidelines are fairly recent documents, the standard methodology for estimating Greenfield flows dates back to the results of studies from the 1970s. The recommendation of the guideline method was not the result of any testing and calibration but rather the assumption that it produced Greenfield flow estimates that were in the order of what would be expected. Experience of Greenfield peak flow estimates using the approved method has shown flows to be very low compared with what would be expected where a detailed knowledge of the site hydrology was available or from observational evidence of flooding events. Recent monitoring of surface run-off and drainage using a 1-min temporal resolution at the Rowden Moor Drainage Experiment at North Wyke Research, Devon, UK has provided an ideal dataset through which to test the current approved methodology for Greenfield flow estimation. The results show that the methods significantly underestimate the Greenfield peak flows.
\end{abstract}

\section{Introduction}

The management of flood risk has become an integral part of new developments in the UK following its inclusion within the planning process through the government documents Planning Policy Guidance 25 (Office of the Deputy Prime Minister, 2000) and Planning Policy Statement 25 (Department for Communities and Local Government, 2006). These documents state that the proper assessment of flood risk must consider the current risk of flooding at the development site and the risk of flooding that the new development may pose to neighbouring properties. To address the potential increase in flood risk that a new development may create, both the current guidance for flood risk assessments as required by the Environment Agency (EA) in England and Wales [Department of the Environment Food and Rural Affairs/ Environment Agency, (DEFRA/EA), 2005; Construction Industry Research and Information Association (CIRIA), 2007] and the Code for Sustainable Homes (Department for Communities and Local Government, 2008) state that the peak design flow into water courses from the developed site should not exceed those under Greenfield conditions. In order to achieve this, sustainable drainage systems (SuDS) need to be incorporated into the design to attenuate the predicted post-development peak flow and to store the excess volume of surface run-off. A key part of the SuDS design is to give an accurate estimate of the Greenfield flow.

\section{Current recommended methodology}

The preferred methodology which is used to calculate the Greenfield peak flow is that which resulted from a study undertaken by the Institute of Hydrology (IH) to estimate flows in small catchments. The method is often referred to as 'IH Report 124' as this was the name of report in which it was described (Marshall and Bayliss, 1994). As part of this study, a simple formula was derived which could be used to calculate the mean annual flood (Qbar) from catchments ranging between 0.5 and $20 \mathrm{~km}^{2}$ :

Qbar $=1.08(A / 100)^{0.89} S A A R^{1.17} S P R^{2.17}$ 
Where $A$ is the catchment area in hectares, the standard annual average rainfall (SAAR) in $\mathrm{mm}$, and the specific percentage run-off (SPR), which itself depends on a classification of five soil types for the whole of the UK.

For development areas which are less than $0.5 \mathrm{~km}^{2}$ (50 ha), the DEFRA/EA guidelines recommend the equation uses 50 ha, and then an aerial proportional relationship should be applied, e.g. for 1 ha:

$\operatorname{Qbar}(1$ ha $)=$ Qbar $(1 / 50)$

To meet the requirements of the EA or Code for Sustainable Homes, the 1 in 100 year peak Greenfield flow needs to be calculated. The DEFRA/EA guidelines recommend this flow is derived from the Qbar using a regional growth curve approach from the Flood Studies Report (FSR) [Natural Environment Research Council (NERC), 1975], with the actual growth factors taken from a later supplementary report to the FSR (Institute of Hydrology, 1983).

\section{Limitations of the current methodology}

The IH Report 124 method is recommended by the EA and forms the basis of SuDS design courses in the UK run by other organisations such as CIRIA. Many professionals who use this method such as drainage engineers and landscape architects do not have a detailed knowledge of hydrology and accept it as best practice. For hydrologists, however, the use of this method is highly questionable. First, many of the parameters are the results of the FSR which has been replaced as the standard flood estimation methodology in the UK by techniques provided in the Flood Estimation Handbook (FEH; Institute of Hydrology, 1999). The FEH techniques use geographical information systems and computer programmes to automate the derivation of catchment parameters and calculation of design flows. By contrast, the methods used in the IH Report 124 require paper maps, look-up tables and estimation of parameter values by eye from plotted relationships. These will all contribute to the uncertainty of the estimate. The DEFRA/EA guidelines state that the procedure is an interim method and anticipates that this will be updated, but nothing new has been published in the years following the report.

The use of regional growth curves to simply convert the 2-year to the 100-year flow is also an aspect of the FSR which has since been replaced by more accurate methods from the FEH. Furthermore, the regional curves are meant for estimating design floods for catchments over $20 \mathrm{~km}^{2}$ and therefore perhaps not applicable for the development site scale (e.g. 1 ha). The IH Report 124 method only derives a peakflow magnitude, not a hydrograph or the duration of the flood. The duration of the flow is required in order to derive a flood storage volume. Therefore, any calculations of storage volumes made using the IH Report 124 method must

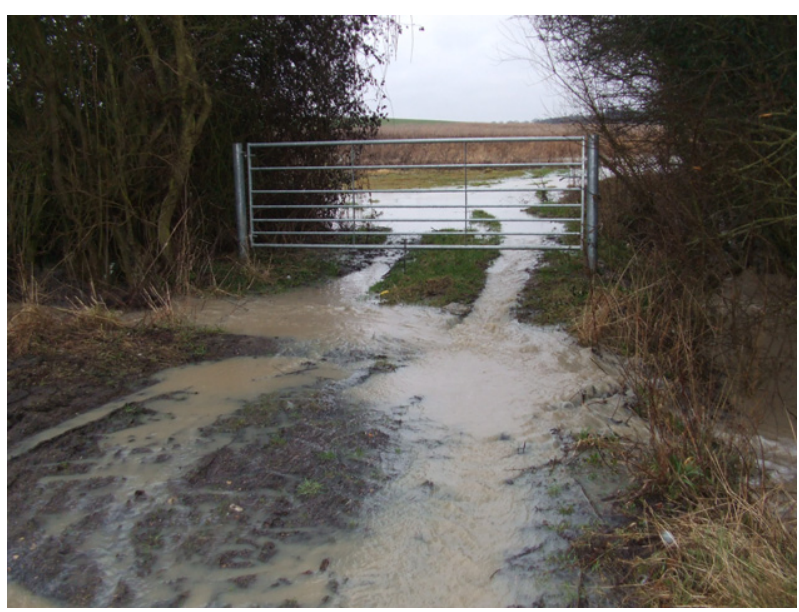

Figure 1 Surface run-off from agricultural land following $15 \mathrm{~mm}$ of rainfall in $12 \mathrm{~h}$.

make an assumption of how long the Greenfield peak flow will be maintained, which could be highly inaccurate.

In addition, the IH Report 124 method was designed for catchments down to $0.5 \mathrm{~km}^{2}$ (50 ha) and not considered appropriate for smaller areas. Nothing in the report recommends its application to the plot scale, and this is also not recommended by Institute of Hydrology (now Centre for Hydrology and Ecology) staff. The DEFRA/EA guidelines, however, recommend this method for estimating Greenfield peak flow from smaller areas (down to $<1$ ha) by assuming a simple area proportional relationship. In this way, it was assumed that the same method for estimation of stream flow in a small catchment would therefore be used to estimate the surface run-off from a homogeneous Greenfield development site. An immediate problem from this assumption is that a small catchment may well have a range of slopes, geology, soil and land use, but a development area of less than one hectare is most likely to be uniform in these aspects. It is often the case that developments of this size occur on farms where poor quality grazing land is used for new buildings. Such land selected for development often has uniform slope, soil, geology and vegetation.

There are other concerns over the accuracy of the IH Report 124 method; it has never been tested for sites less than $0.5 \mathrm{~km}^{2}$, and during wet conditions in rural areas, it is common to see water streaming off agricultural land at a rate much greater than the IH Report 124 predictions would suggest (Figure 1). The amount of surface water flooding associated with the summer 2007 floods in the UK (Marsh and Hannaford, 2007) also raised concerns about the methods used to predict surface run-off from rural areas. The effect of antecedent conditions is not explicitly included in the IH 124 method; this is just represented in the formula by the SAAR. It is, however, when soils are saturated that the 
greatest surface run-off is experienced such as is shown in Figure 1.

In addition, in terms of the application of models to estimate Greenfield and developed site run-off, the IH 124 method cannot be used to consider the Qbar from the developed land as it has no way of representing flow from an impermeable surface.

In flood risk assessments or the surface water management for sustainable homes, the peak flow from the developed site is required to be calculated from a design rainfall derived from the FEH. A simple rational rainfall run-off method is commonly applied to derive the peak flow from the developed site:

$Q_{p}=0.28 C i A$

Where $Q_{p}$ is the peak flow in cumecs, $C$ is the percentage surface run-off, $i$ is the peak rainfall intensity $(\mathrm{mm} / \mathrm{h})$ and $A$ is the area of the catchment $\left(\mathrm{km}^{2}\right)$. The use of the two different methods, the empirical IH 124 method and a rational method based on rainfall data further increases the uncertainty of the outputs. For modelling studies, in order to reduce uncertainty, it is always best practice to use the same model for different scenarios.

The SuDS design should then include measures to attenuate the post-development peak flow to ensure that the eventual discharge to watercourses does not exceed the Greenfield design flow. These are often soakaways, storage ponds or grass swales. The excess storage volumes required for the SuDS features being the difference between the volume of run-off from the post development and Greenfield sites.

The EA guidelines also describe the use of another method for predicting the peak flow from small areas. This is the Agricultural Development and Advisory Service (ADAS) 345 method (ADAS, 1981), developed for the purpose of estimating the required capacity of field drainage. It is more physically based than IH Report 124, including slope, land use and soil characteristics and intended for areas up to $30 \mathrm{ha}$. The calculation, however, uses the SAAR rather than a design rainfall and again the output is not as a hydrograph but purely the magnitude of the mean annual (1-year) peak flow.

$Q=S T F A$

Where: $Q$ is the 1-year peak flow in 1/s; $S T$ is the soil-type factor which ranges between 0.1 for a very permeable soil and 1.3 for an impermeable soil; $F$ is a factor, which is a function of the average slope, maximum drainage length and average annual rainfall obtained from using a nomograph; and $A$ is the area of the catchment being drained in hectares. The use of nomographs to derive the peak flow by eye is prone to error and the design flow (e.g. 100 years) as with the IH Report 124 method is simply derived through multiplying the 1-year peak flow by 1.14 to obtain the 2-year peak flow and then the
FSR growth factor. Like the IH 124 method, there is no explicit representation of the antecedent conditions, again these are represented by the average annual rainfall at the site. The EA guidelines recommend the use of IH method 124 in preference to the ADAS method for estimating Greenfield peak flow due to the easier calculations. The Code for Sustainable Homes follows this recommendation.

Outside of the UK, estimates of surface run-off are commonly made using the rational formula as shown in Eqn (3) above, but this is often modified to incorporate the effect of storage or to consider increments of different intensity rainfalls over the duration of the storm and are listed in standard drainage design guidelines throughout North America (Schueler and Claytor, 2000; Lucas, 2002). Another North American technique, which originates from the US Department of Agriculture Natural Resources Conservation Service is the application of the run-off curve number (USDA Natural Resources Conservation Service, 1986). This has been incorporated into field scale modelling packages such as Groundwater Loading Effects of Agricultural Management Systems (Knisel, 1993) although with a relatively coarse temporal resolution of one day, it is more suited to seasonal or annual outputs rather than design storms.

\section{Testing of the current methodology}

Neither of the recommended UK methods given above have been tested against measured data at the 1 ha scale. Recent high-resolution monitoring of flows and rainfalls at the Rowden Drainage Experiment has enabled the use of observed data from a 1 ha plot to test the accuracy of both the IH Report 124 and ADAS 345 methods.

\section{Study area details}

Hydrological data were obtained from a site known as the Rowden Drainage Experiment, which was established in 1982. This is an area of typical UK upland grazing, located at $3^{\circ} 55^{\prime} \mathrm{W}, 50^{\circ} 47^{\prime} \mathrm{N}$ on the edge of the Dartmoor National Park in Devon, south-west England (Figure 2). The site was set up on an area of previously unimproved and poorly drained pasture land on the farm at North Wyke Research, Okehampton, Devon, previously known as Rowden Moor. The altitude of the site is $180 \mathrm{~m}$ above sea level, and the ground has a slope of $5 \%-10 \%$ from west to east. The 40 -year mean annual rainfall (1961-2000) for this area is $1055 \mathrm{~mm}$. The soil is predominantly a clayey non-calcareous pelostagnogley of the Hallsworth series overlying the clay shales of the Crackington Formation also described as a Dystric Gleysol (FAO-UNESCO, 1974), and is typical of much of the permanent grassland in the south-west of England. The combination of high annual rainfall coupled with a clay subsoil 


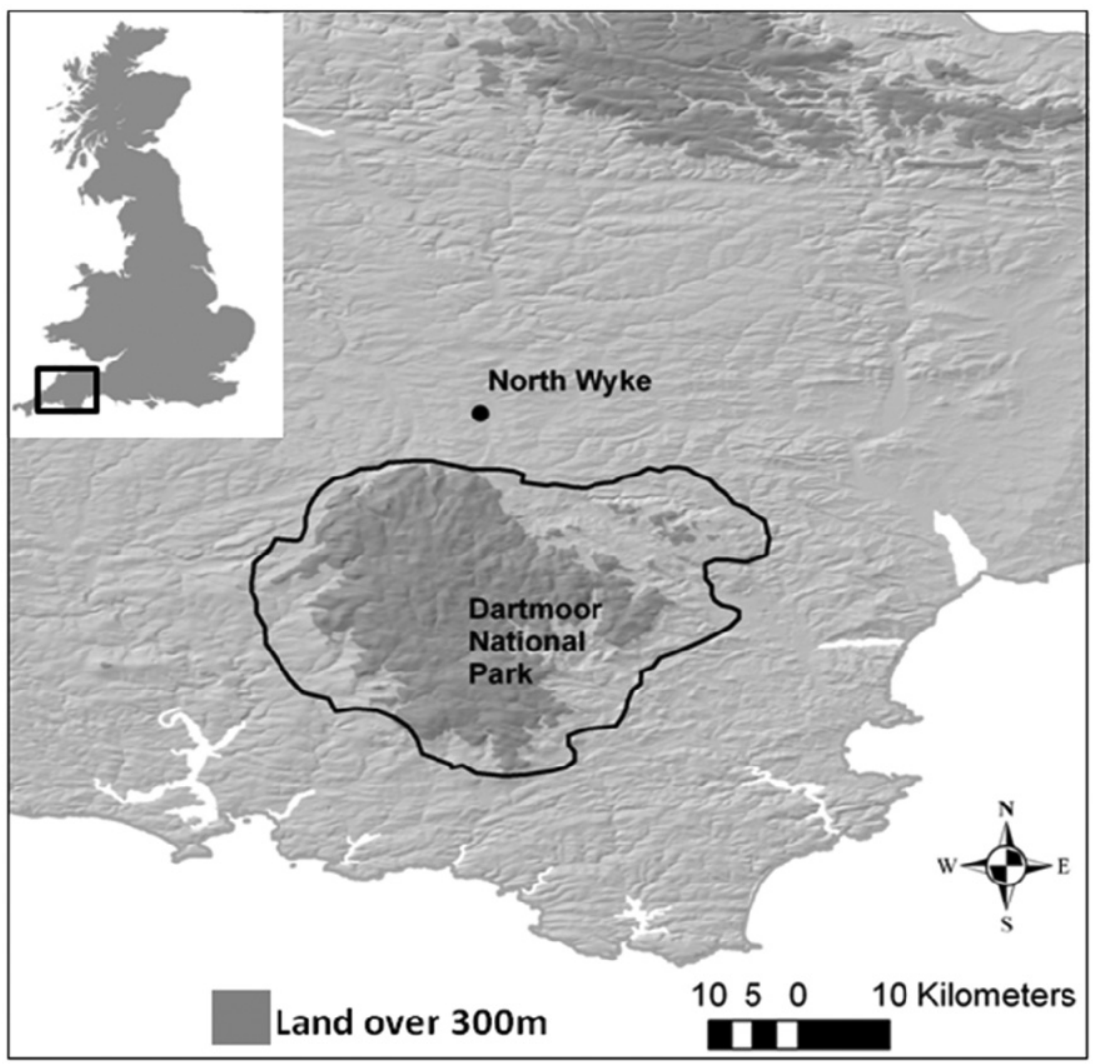

Figure 2 The location of North Wyke.

and $<10 \mathrm{~mm} / \mathrm{d}$ hydraulic conductivity (Armstrong and Garwood, 1991), means that, for much of the winter season, the soils are waterlogged. As a result, excess rainfall is only removed from undrained soil via overland surface run-off and subsurface lateral flow down to approximately $30 \mathrm{~cm}$.

\section{Experiment design}

The design of the Rowden Drainage Experiment originally consisted of 12 lysimeter (i.e. hydrologically isolated plots) in two blocks of six, each of 1 ha. In 1987, a previously unfertilised area of adjacent permanent pasture was incorporated in order to provide two plots each of 0.66 ha (Tyson et al., 1993) that are continuously managed with zero input of mineral $\mathrm{N}$ fertilizer, thus giving a total of 14 plots (Figure 3).

Each lysimeter plot is bounded by gravel interceptors to isolate overland surface run-off and surface lateral flow (to $30 \mathrm{~cm}$ ) so that each lysimeter is hydrologically isolated from its neighbour. Half of the lysimeters (seven) are also drained to $85 \mathrm{~cm}$ by tile drains at $40 \mathrm{~m}$ intervals across the slope, overlain by mole drains at $2 \mathrm{~m}$ spacing and a depth of $55 \mathrm{~cm}$ down the slope (Figure 4). This design represents a typical form of field drainage management under these soil and hydrology conditions (Armstrong and Garwood, 1991).

\section{Monitoring details}

Pipe diameters of 100, 160 and $200 \mathrm{~mm}$ are used to convey the surface and subsurface drainage from the plots, depending on the gradient and area which they drained. Water draining as either surface run-off, subsurface lateral flow or through field drains is channelled from each individual plot using $1 / 290^{\circ} \mathrm{V}$-notch weirs (BSI, 1981) with 21 weirs in total. Each of the weirs is fitted with a Precision Water Level Model 6541 sensor (Unidata, O'Connor, Western Australia). The instrument consists of a float which rests on the surface of the water within a stilling well, sited in the weir. Attached to the top of the float is a wire which passes up over a pulley and optical encoder, and is attached to a counter balance weight. As the water level, or stage, changes the pulley and encoder rotate so that the instrument continuously tracks water level changes. The very low mechanical friction and inertia of the instrument mean that it can produce data with high precision and accuracy $( \pm 0.2 \mathrm{~mm})$. The stage height changes are logged at 1 min intervals by a radio logger (Model CR215, Campbell Scientific, Loughborough, UK), and the data from 


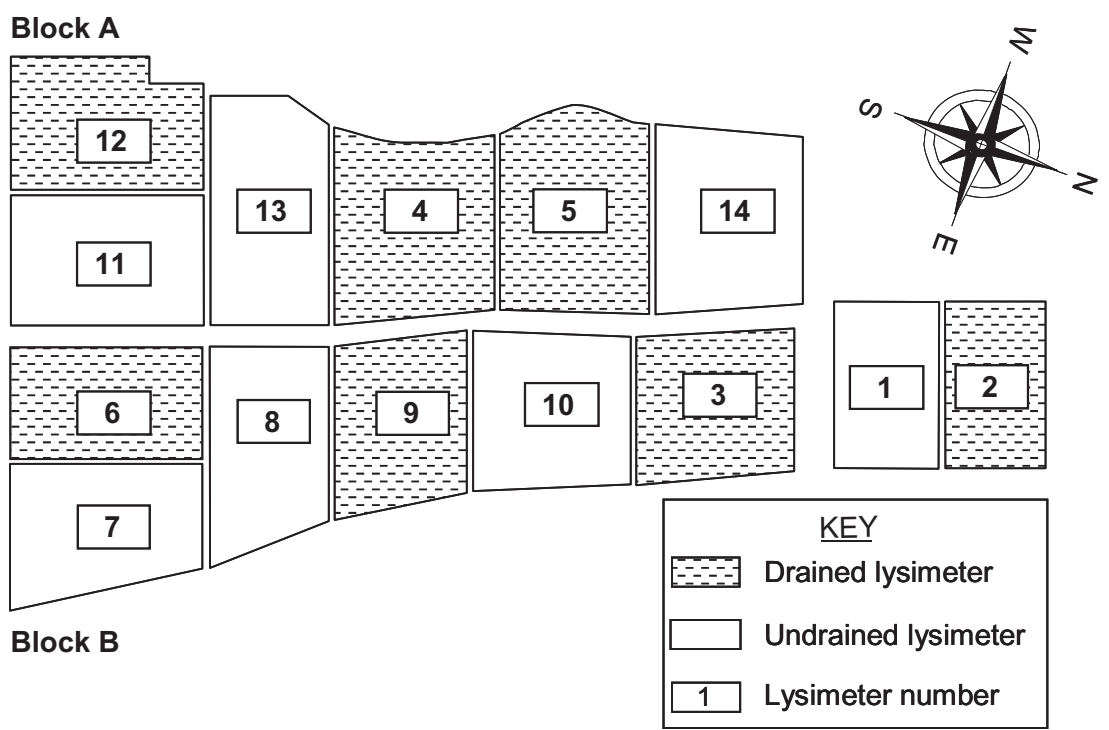

Figure 3 Design of the Rowden Drainage Experiment.

each weir are transmitted via an RF modem to a PC housed on the site. The stage data are manually downloaded from the PC at weekly intervals and are checked for quality assurance using a suite of Matlab programmes that were specifically written for this purpose. The programmes check for missing or repeated time steps (clock drift), calculate the discharge according to stage-discharge rating curves obtained by manual calibration of the weirs and calculate the discharge uncertainty intervals for each of the data points using a procedure described in Krueger et al. (2009).

\section{Flow calculations}

\section{Predicted flows}

Data for the current study were provided for plot 8 from the Rowden Moor experiment. The Greenfield flow calculations using the IH Report 124 and ADAS345 methods were undertaken using the parameter values listed in Tables 1 and 2 . The results are listed in Table 3.

\section{Observed flows}

The largest 10 events were extracted from the observed flows over the period September 2006-December 2008. In each case, the average flow was calculated from a minimum and maximum value assumed from the range of uncertainty pertaining to the flow measurement. These are listed in Table 4, although the peak flows from the events of 12 March 2006 and 6 February 2008 were likely to be even higher as on both of these occasions, the stage height values exceeded the maximum limit of the stage-discharge rating curve (at $75 \mathrm{l} / \mathrm{s}$ ) and thus were discarded from the dataset. For the
December 2006 event, 17 null values were recorded between flows of 48.8 and 57.2 1/s, whereas for the June 2008 event, 49 null values were recorded between flows of 51.1 and $52.11 \mathrm{l} / \mathrm{s}$. Looking at the hydrographs (Figures 5 and 6 ) and in particular the length of the period when the maximum stage height was exceeded, the June 2008 event may well have been the most severe. During this event, the whole of the monitoring station was flooded.

\section{Comparison of flows}

A comparison of Tables 3 and 4 shows that the maximum flow observed at Rowden Moor during the period September 2006-December 2008, of at least $57.2 \mathrm{l} / \mathrm{s}$, considerably exceeds the predicted 100-year flows calculated using the IH Report 124 method. In fact, the IH Report 124 100-year flow is exceeded by six of the 10 flows listed over the study period, the maximum of the observed flows being at least over three times the predicted 1 in 100-year flow of 18.9 1/s. The predicted mean annual flow of $7.8 \mathrm{l} / \mathrm{s}$ is exceeded by all of the 10 events, and probably by a number of other observed events which were not considered severe enough to be listed.

The ADAS 345 method is closer to the observed values although still an underestimate. It predicts a maximum 1 in 100-year flow of $69.2 \mathrm{l} / \mathrm{s}$, which is in the order of the maximum observed flows and also over a factor of three times higher than that predicted by the IH Report 124 method. However, a predicted 1 in 100 -year flow which is exceeded by two events in the space of 2.5 years is still highly questionable. The ADAS 1-year peak flow is exceeded by four events over the study period.

This comparison shows that neither method predicts reliable 100-year Greenfield flows and that the IH Report 124 method is particularly poor. A proper assessment of the 

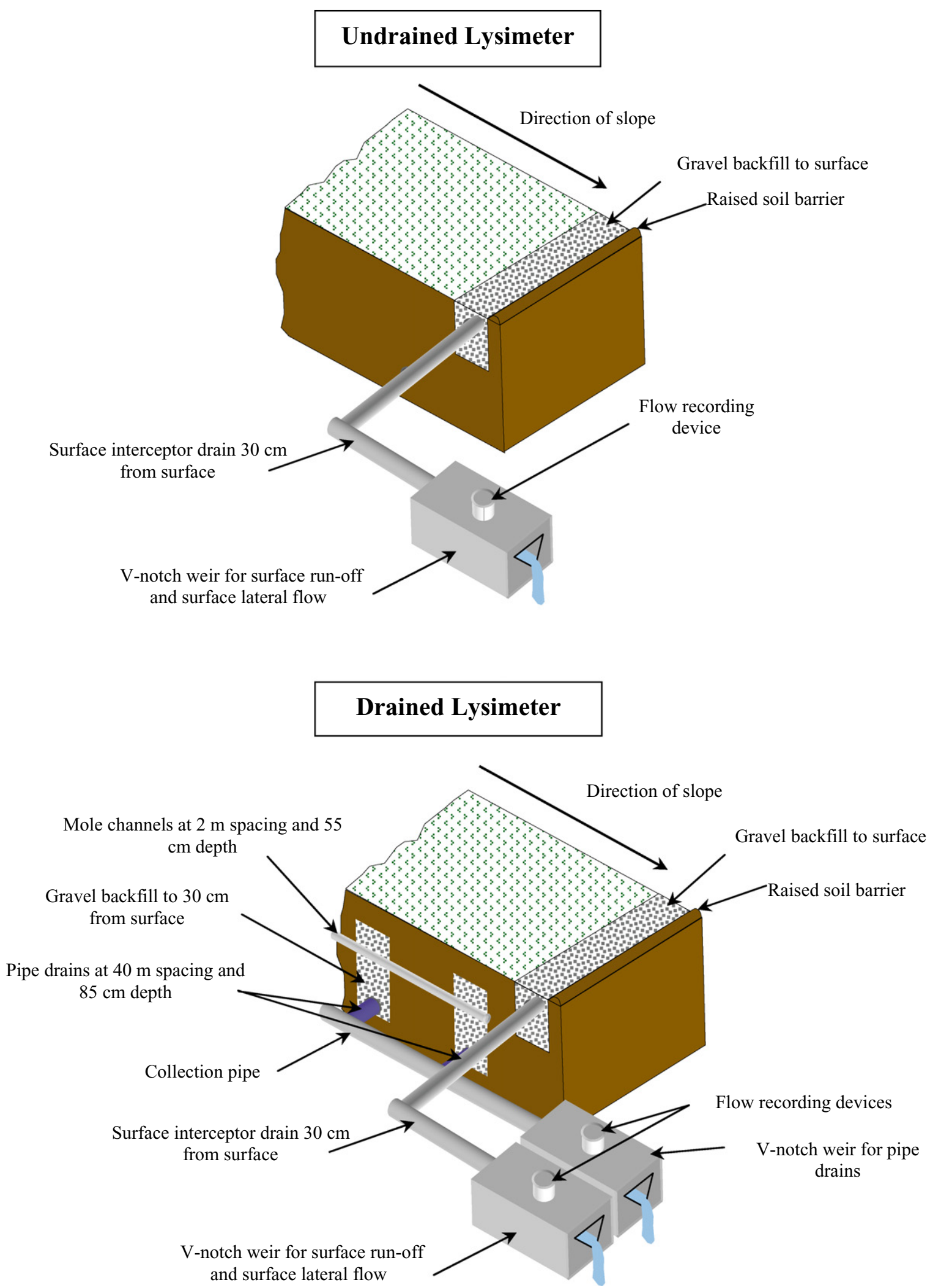

Figure 4 Schematic cross section through an undrained and a drained lysimeter to show collection and channelling of surface run-off, subsurface lateral flow and drainage waters to V-notch weirs. 
Table 1 Parameter values and sources for the IH Report 124 method

\begin{tabular}{lcl}
\hline Parameter & Value & Source \\
\hline Hydrological region & 8 & DEFRA/EA \\
Wrap class & 4 & FSR \\
Area & 50 & DEFRA/EA \\
SAAR & $1055 \mathrm{~mm}$ & Site records \\
SPR & 0.47 & DEFRA/EA \\
Growth factor & 2.42 & FSR supplementary \\
& & report \\
\hline
\end{tabular}

DEFRA/EA, Department of the Environment Food and Rural Affairs/ Environment Agency; IH, Institute of Hydrology; FSR, flood studies report; SAAR, standard annual average rainfall; SPR, specific percentage run-off.

Table 2 Parameter values and sources for the ADAS 345 method

\begin{tabular}{lcl}
\hline Parameter & Value & Source \\
\hline Slope & $0.067 \mathrm{~m} / \mathrm{m}$ & Site records \\
Drainage length & $182 \mathrm{~m}$ & Site records \\
SAAR & $1055 \mathrm{~mm}$ & Site records \\
Land use & Grass & Site records \\
Area & 1 & Site records \\
St & 1 & ADAS tables \\
F & 25.1 & ADAS nomograph \\
Growth factor & 2.75 & FSR supplementary \\
& & report (adjusted) \\
\hline
\end{tabular}

ADAS, Agricultural Development and Advisory Service; F, factor; FSR, flood studies report; SAAR, standard annual average rainfall; St, soil-type factor.

Table 3 Predictions of Greenfield flows from the Rowden Moor site

\begin{tabular}{lcc}
\hline Method & Qbar (I/s) & Q100 (I/s) \\
\hline IH Report 124 & 7.8 & 18.9 \\
ADAS 345 & 25.1 & 69.2 \\
\hline
\end{tabular}

ADAS, Agricultural Development and Advisory Service; IH, Institute of Hydrology.

return periods of the Rowden Moor flows is not possible given the short period of monitoring, however, given that flows exceeded $75 \mathrm{l} / \mathrm{s}$ on two occasions over the 2.5 -year monitoring period, it is reasonable to assume that a mean annual flow would exceed $25 \mathrm{l} / \mathrm{s}$ (the highest of the predicted values). Prior to 2006, the temporal resolution of the flow monitoring was much less frequent, with run-off totals calculated on a daily basis. However, field staff noted that the weirs have been completely flooded out on another four occasions during the 20-year period since the monitoring was started. Thus, six events in total over $75 \mathrm{l} / \mathrm{s}$ have occurred during a period of 22.5 years. This shows that on average a flow in excess of $75 \mathrm{l} / \mathrm{s}$ will occur once every 3.75 years, hence a return period of 3.75 years.

A further analysis of the observed events can be made in terms of the storm generating rainfall using the FEH Depth
Table 4 Peak observed flows from plot 8 over the period September 2006-December 2008

\begin{tabular}{lc}
\hline Date and time & Plot 8 peak flow $(1 / / \mathrm{s})$ \\
\hline $03 / 12 / 200604: 21$ & $57.2^{*}$ \\
$02 / 06 / 200816: 12$ & $52.1^{*}$ \\
11/01/2007 11:42 & 34 \\
30/11/2007 17:10 & 26.6 \\
05/09/2008 16:38 & 22.5 \\
15/07/2007 09:01 & 19.2 \\
10/03/2008 03:08 & 18.5 \\
15/06/2007 13:58 & 17.6 \\
13/05/2007 10:23 & 16 \\
29/05/2008 23:32 & 14.6 \\
\hline
\end{tabular}

*Weir maximum capacity of $75 \mathrm{l} / \mathrm{s}$ exceeded.

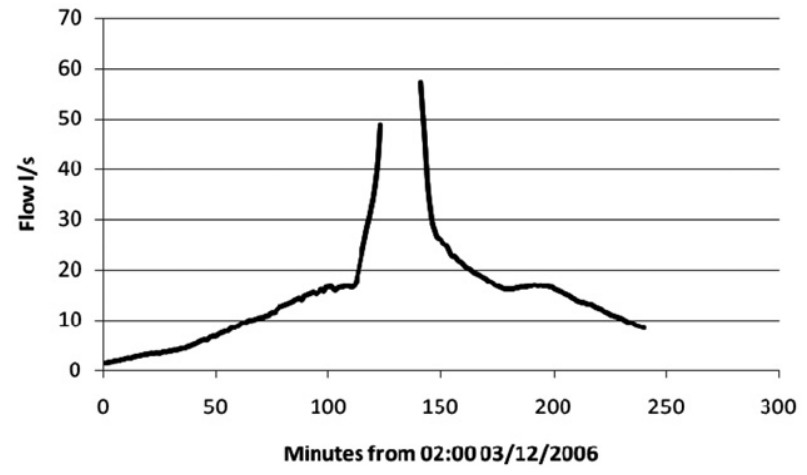

Figure 5 Observed hydrograph from 3 December 2006.

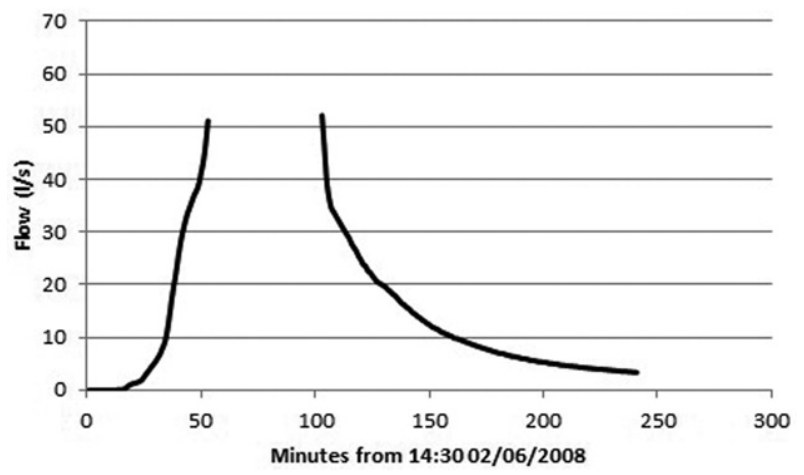

Figure 6 Observed hydrograph from 2 June 2008.

Duration Frequency (DDF) rainfall model. Here, it is possible to estimate return periods of the rainfall associated with the 10 flood events. The six-hourly rainfall up to the time when the peak flow and the maximum 1-hourly fall for each event were taken from hourly rainfall depth measurements from the North Wyke automatic weather station. These are listed in Table 5.

The results of the FEH DDF (Table 6) model show the observed rainfalls are not particularly extreme, and that a 
Table 5 6-hourly and hourly maximum rainfalls associated with the maximum observed flow events

\begin{tabular}{lcc}
\hline Event & 6-hourly fall $(\mathrm{mm})$ & Maximum hourly fall $(\mathrm{mm})$ \\
\hline $03 / 12 / 2006$ & 25.2 & 12.2 \\
$11 / 01 / 2007$ & 15.4 & 11.4 \\
$15 / 07 / 2007$ & 15.8 & 6.6 \\
$15 / 06 / 2007$ & 15.4 & 4.0 \\
$13 / 05 / 2007$ & 26.8 & 10.2 \\
$30 / 11 / 2007$ & 20.8 & 13.4 \\
$10 / 03 / 2008$ & 15.6 & 8.4 \\
$29 / 05 / 2008$ & 18.4 & 6.2 \\
$02 / 06 / 2008$ & 43.6 & 23.0 \\
$05 / 09 / 2008$ & 13.8 & 11.4 \\
\hline
\end{tabular}

100-year, 1-h and 6-h fall are approximately 50\% and 40\% greater respectively than the maximum observed falls over the duration of the monitoring. It is therefore feasible that the 100-year rainfall would produce significantly greater flows than the highest observed in 2006-2008 in the order of hundreds 1/s. These would far exceed the IH Report 124 and ADAS 345 method estimates.

A comparison of the measured flows at North Wyke with other experimental sites shows that they are in a similar range. Although no other data for similar spatial and temporal resolution was found for the UK, field experiments in Belgium (Laloy and Bielders, 2008) and Northern France (Léonard et al., 2006) with similar climatic conditions measured peak flows of up to $200 \mathrm{l} / \mathrm{s} / \mathrm{h}$. Further studies in Mediterranean France (Chahinian et al., 2006) observed flows of up to $50 \mathrm{l} / \mathrm{s}$ from a 0.34 ha plot over the period October 1993-November 1997. Finally, monitoring of a 3 ha hill slope in New Zealand, in a similar climatic zone to North Wyke had a maximum annual flow of $273 \mathrm{l} / \mathrm{s}$ following rainfall totalling $31 \mathrm{~mm}$ in $12 \mathrm{~h}$ (Rodda et al., 1996).

\section{Discussion}

The particularly poor performance of the IH 124 method at predicting the Greenfield flows at Rowden Moor is likely to be a result of the limitations of the method as described in the introduction. The assumption that a method derived from observed stream flow data for catchments ranging between 0.5 and $20 \mathrm{~km}^{2}$ can be used at a 1ha-sized plot by taking an area proportional relationship is unrealistic and does not demonstrate an understanding of catchment hydrology. The time lag and attenuation associated with the stream flow even in a small catchment will have a considerable impact so that the peak flow measured in a stream, and averaged on a per hectare basis, would be considerably less than that coming off a one hectare plot.

The simple empirical relationship of the IH 124 method also exhibits a lack of robustness. The difference in slope and land use can have particularly significant effects at the plot scale. Field staff at North Wyke has observed much greater surface run-off from steeper slopes. This is demonstrated by observations from a neighbouring plot (plot 11) which has a slightly lower slope. The peak flow for 3 December 2006 was only $38.1 \mathrm{l} / \mathrm{s}$, some $30 \%$ less than the maximum observed flow of $57.2 \mathrm{l} / \mathrm{s}$ from plot 8 . The IH 124 method would give the same peak flow for plots even if the slope was significantly different. The ADAS 345 method which includes the effect of slope is more robust in this area and estimates for the neighbouring plots gave only a slight variation in the 100 -year peak flow $38.7 \mathrm{l} / \mathrm{s}$ for plot 11 compared with $41.2 \mathrm{l} / \mathrm{s}$ for plot 8 .

Likewise, the IH 124 method can not account for differences in land use which can also show considerable differences in surface run-off. The plots at North Wyke have been grazed by cattle which prefer long grass and also tend to be selective so that a reasonable thickness of sward is maintained. Sheep and horses nibble grass to very much shorter lengths and can create patches of bare ground, which provides much less surface roughness to resist the overland flow of water. Eye observations from other parts of North Wyke grazed by sheep have noted much higher surface run-off than from the longer grass of the cattle plots. The ADAS method does give three classes of land use, (arable, horticulture and grassland) but cannot consider the differences between grazing animals.

Both the ADAS and IH 124 methods rely on growth curves to convert the 1 or 2-year peak flow into 100 -year peak flows which have been taken from the FSR. These curves are assigned on a regional basis and again are neither robust nor appropriate in terms of the hydrology. The regional curves were derived based on flows in rivers draining catchments greater than $20 \mathrm{~km}^{2}$. The relationship between a mean annual flow and a 100-year flow for a smallscale plot is likely to be very different from that for a river catchment. Also the regional curves do not account for differences in catchment characteristics for example, if two catchments were in the same region but drained impermeable clay or permeable chalk areas, the growth curves would be the same. Such regional growth curves have been replaced for UK flood estimation by pooling methods given in the FEH which group observations from catchments of similar characteristics.

\section{Sustainable drainage design implications}

The results from the North Wyke study have particularly serious implications in relation to the design of sustainable drainage systems. The current guidelines require that peak flow from a developed site should not exceed the Greenfield peak flow as calculated by the IH Report 124 method. The design therefore is based on a predicted value which could well be an order of magnitude lower than the actual value. 
Table 6 Predicted and observed rainfall return periods and magnitudes and return periods derived using the FEH DDF model

\begin{tabular}{lccc}
\hline Rainfall & Duration $(\mathrm{h})$ & Return period (years) & Rainfall (mm) \\
\hline FEH estimate & 1 & 100 & 45.6 \\
FEH estimate & 6 & 100 & 72.4 \\
Observed 03/12/2006 & 1 & 1.6 & 12.2 \\
Observed 03/12/2006 & 6 & 1.2 & 25.2 \\
Observed 02/06/2008 & 1 & 9.5 & 23.0 \\
Observed 02/06/2008 & 6 & 12.5 & 43.6 \\
Observed 13/05/2007 & 6 & 1.6 & 26.8 \\
\hline
\end{tabular}

DDF, depth duration frequency; FEH, flood estimation handbook.

This could lead to a significant underestimate of the flood risk where Greenfield areas are incorporated as part of the SuDS design. For example, many larger developments include landscaped areas of greenery surrounding offices and car parks which are assumed to reduce the overall surface run-off from the site. However, if the potential surface run-off from these areas was calculated using the IH Report 124 method, then in reality, the surface run-off could be 10 times the design value potentially leading to a serious risk of flooding at the site.

Alternatively, where Greenfield areas have been replaced with impermeable surfaces such as roofs, roads and car parks, the SuDS design has to limit the peak flow from the site to the Greenfield peak flow as calculated by the IH Report 124 method. The difference between the peak flow from the developed site (usually calculated using design rainfall and the application of the rational method) and Greenfield flow will have to be stored on site in storage ponds or grass swales. First, a problem is encountered with the use of the IH Report 124 method since it only predicts a single peak flow values rather than a hydrograph, so an estimate of the time is required to derive the volume relating to the flood event. This is often assumed to be the same as the design rainfall duration used to predict the developed site flows, which can lead to highly uncertain estimates. Significant underestimates of the Greenfield peak flow would mean a much greater storage volume is required leading to unnecessary costs for the developer.

\section{Conclusions}

This study has shown the current approved UK methods of estimating peak flow from small Greenfield sites to be a considerable underestimate compared with measurements from an experimental site. The application of these methods to sustainable drainage design can lead to potential increases in the risk of surface water flooding and a costly over-design where the design peak flows are likely to be significant underestimates. A fuller study is recommended to include observations over a longer time period than the 2.5 years where data were available for the current study and to make use of measurements from more plots at the experimental site (only results from one out of 14 plots were used). It would also be desirable to gather data from other similar plot-sized experiments which may have been undertaken at other locations within the UK to incorporate a wider range of climate, soils, topography and land use. Finally, given the high-resolution data, which are available from the experimental site, it would be interesting to test widely used physically based rainfall run-off models such as the Système Hydrologique Europèen model (Abbott et al., 1986) or Hydrologiska Byråns Vattenbalansavdelning model (Bergström, 1976).

\section{References}

Abbott M.B., Bathurst J.C., Cunge J.A., O’Connell P.E. \& Rasmussen J. An introduction to the European system: Systeme Hydrologique Europeen (SHE). J Hydrol 1986, 87, 61-77.

ADAS. 1981. The design of field pipe drainage systems. MAFF Report 345.

Armstrong A.C. \& Garwood E.A. Hydrological consequences of agricultural drainage. Hydrol Process 1991, 5, 157-174.

Bergström S. 1976. Development and application of a conceptual runoff model for Scandinavian catchments. SMHI Reports RHO, No. 7, Norrköping.

BSI. Methods of measurement of liquid flow in open channels. Part 4A: weirs and flumes; Thin plate weirs and Venturi flumes. BS 3680. London: British Standards Institution, 1981. Chahinian N., Moussa R., Andrieux P. \& Voltz M. Accounting for temporal variation in soil hydrological properties when simulating surface runoff on tilled plots. J Hydrol 2006, 326, 135-152.

Construction Industry Research and Information Association (CIRIA). 2007. The SUDS manual. CIRIA Publication C697, London.

Department of the Environment Food and Rural Affairs/ Environment Agency (DEFRA/EA). 2005. Preliminary rainfall runoff management for developers. R\&D Technical Report W5-074/A/TR/1, London.

Department for Communities and Local Government. Planning policy statement 25: development and flood risk. London: Eland House, Bressenden Place, 2006. 
Department for Communities and Local Government. Code for Sustainable Homes (CSH) technical guide October 2008. London: Eland House, Bressenden Place, 2008.

FAO-UNESCO. Soil map of the world. 1:5,000,000. Vol. 1 Legend. Paris: UNESCO, 1974.

Institute of Hydrology. Flood studies supplementary report review of regional growth curves. Oxfordshire, UK: Wallingford, 1983.

Institute of Hydrology. Flood estimation handbook. 5 Volumes, Wallingford, Oxfordshire, UK: Institute of Hydrology, 1999.

Knisel W.G. 1993. GLEAMS - groundwater loading effects of agricultural management systems. UGA-CPES-BAED Publication No. 5, Tifton, GA.

Krueger T., Quinton J.N., Freer J., Macleod C.J.A., Bilotta G.S., Brazier R.E., Butler P. \& Haygarth P.M. Uncertainties in data and models to describe event dynamics of agricultural sediment and phosphorus transfer. J Environ Qual 2009, 38, 1137-1148.

Laloy E. \& Bielders C.L. Plot scale continuous modelling of runoff in a maize cropping system with dynamic soil surface properties. J Hydrol 2008, 349, 455-469.

Léonard A., Ancelin O., Ludwig B. \& Richard G. Analysis of the dynamics of soil infiltrability of agricultural soils from continuous rainfall-runoff measurements on small plots. J Hydrol 2006, 326, 122-134.

Lucas W.C. DURMM: Delaware urban runoff management model users manual. Dover, DE: Delaware Department of Natural Resources and Environmental Conservation, 2002.
Marsh T.J. \& Hannaford J. The summer 2007 floods in England and Wales - a hydrological appraisal. Wallingford, Oxfordshire, UK: Centre for Ecology and Hydrology, 2007.

Marshall D.C.W. \& Bayliss A.C. 1994. Flood estimation for small catchments. Institute of Hydrology Report 124, Wallingford, Oxfordshire, UK.

Natural Environment Research Council (NERC). The flood studies report. 5 Volumes. London: Her Majesty's Stationary Office, 1975.

Office of the Deputy Prime Minister. Planning policy guidance 25: development and flood risk. London: Eland House, Bressenden Place, 2000.

Rodda H.J.E., Stroud M.J. \& Latimer G.J. 1996. Report on the field and modelling experiments at Whatawhata 1995/6. NIWA Internal Report No.IR96/17, Hamilton, New Zealand.

Schueler T.R. \& Claytor R.A. Maryland stormwater design manual. Baltimore, MD: Maryland Department of the Environment, 2000.

Tyson K.C., Hawkins J.M.B. \& Stone A.C. Final report on the AFRC-ADAS drainage experiment 1982-1993. Okehampton, Devon, UK: IGER, North Wyke, 1993.

USDA Natural Resources Conservation Service. Urban hydrology for small watersheds. Technical Release 55, Beltsville, MD, June 1986. 